\title{
Recent Advances in the Synthesis of Graphene-Based Nanomaterials for Controlled Drug Delivery
}

\author{
Zhuqing Wang ${ }^{1,2}$, Lucio Colombi Ciacchi ${ }^{2,3}$ and Gang Wei ${ }^{2, *}$ \\ 1 Anhui Provice Key Laboratory of Optoelectronic and Magnetism Functional Materials, \\ Anqing Normal University, Anqing 246011, China; wangzhuqing@nimte.ac.cn \\ 2 Hybrid Materials Interfaces Group, Faculty of Production Engineering and Center for Environmental \\ Research and Sustainable Technology (UFT), University of Bremen, D-28359 Bremen, Germany; \\ colombi@uni-bremen.de \\ 3 MAPEX Center for Materials and Processes, University of Bremen, Am Fallturm 1, \\ D-28359 Bremen, Germany \\ * Correspondence: wei@uni-bremen.de; Tel.: +49-421-218-64581
}

Received: 29 September 2017; Accepted: 13 November 2017; Published: 15 November 2017

\begin{abstract}
Graphene-based nanomaterials have exhibited wide applications in nanotechnology, materials science, analytical science, and biomedical engineering due to their unique physical and chemical properties. In particular, graphene has been an excellent nanocarrier for drug delivery application because of its two-dimensional structure, large surface area, high stability, good biocompatibility, and easy surface modification. In this review, we present the recent advances in the synthesis and drug delivery application of graphene-based nanomaterials. The modification of graphene and the conjugation of graphene with other materials, such as small molecules, nanoparticles, polymers, and biomacromolecules as functional nanohybrids are introduced. In addition, the controlled drug delivery with the fabricated graphene-based nanomaterials are demonstrated in detail. It is expected that this review will guide the chemical modification of graphene for designing novel functional nanohybrids. It will also promote the potential applications of graphene-based nanomaterials in other biomedical fields, like biosensing and tissue engineering.
\end{abstract}

Keywords: graphene; modification; nanoparticles; polymer; nanohybrids; drug delivery; biomedical application

\section{Introduction}

The design and fabrication of gene and drug delivery systems with high loading and release performances are important for improving the therapeutic efficiency of diseases [1,2]. Previously, various nanomaterials, such as nanoparticles [3], polymers [4,5], carbon nanotubes [6], and others [7] have been widely used for the controlled drug delivery and release. With the discovery of graphene in 2004 [8], more efforts have been spent to achieve many biomedical applications with graphene-based nanomaterials [9-13].

In 2008, Dai and co-worker for the first time reported the synthesis of nanoscale graphene oxide (GO) for drug delivery application [14]. They found that the polyethylene glycol (PEG)-modified GO could be utilized to load the anti-cancer drug doxorubicin by $\pi$ stacking and kill cancer cells in vitro. After that, graphene has been thought of as an excellent nanocarrier for drug delivery due to several reasons $[15,16]$. Firstly, it has a two-dimensional monolayer structure, which could provide a larger surface area for loading more drug than previous nanocarriers. It has been reported that the loading mass of drugs could reach $200 \%$ of the graphene-based drug nanocarrier [17]. Secondly, graphene has a high chemical and mechanical stability [18], making graphene-based nanomaterials suitable for different delivery environments. Thirdly, though pristine graphene and graphene oxide (GO) have a 
certain toxicity to cells and animals, its stability and biocompatibility can be greatly improved by a simple functionalization process, such as coated with biocompatible substance (polyethylene glycol, dextran, alginate, or biomacromolecules), which could reduce or eliminate the cellular toxicity and negative effects to the human body $[19,20]$. Finally, graphene and its derivatives are easy to modify with covalent and noncovalent methods [21-23], and therefore provide more possibilities to synthesize other functional nanohybrids for drug delivery.

Although graphene and graphene derivatives could be utilized for drug delivery, the loading and release of drug are still difficult to control, such as it generally aggregates in salt or biological solutions and shows a certain degree of cytotoxicity $[14,24,25]$. Therefore, other traditional drug delivery-related nanomaterials, like small molecules, nanoparticles, polymers, and biomacromolecules have been conjugated to graphene to produce novel graphene-based nanohybrids for drug delivery [17,26-28]. Previously, several reviews on the synthesis and modification of graphene-based nanomaterials for drug delivery have been reported [29-32]. For example, Goenka et al., summarized the studies (until 2013) on the synthesis of graphene-based nanomaterials for drug delivery and tissue engineering [30], and Dong et al., demonstrated the current advances in the surface engineering of graphene-based nanomaterials for drug delivery [31]. Although great achievements on the drug delivery application of graphene have been obtained, there is still some space left to make it more clear, especially given the recent developments on the design of novel materials for specific drug delivery.

In this review, we summarized the recent advances (2013-2017) in the synthesis and drug delivery application of graphene-based nanomaterials. We focused on the modification of graphene with other materials, such as small molecules, nanoparticles, polymers, and biomolecules. This review will be helpful for understanding the drug delivery mechanisms of materials, the functionalization of graphene, and the design of functional hybrid nanomaterials for various applications.

\section{Ways of Controlled Drug Delivery}

In contrast to traditional chemotherapy, in which drugs diffuse freely in the bloodstream and are evenly distributed in the entire body, taking advantage of tumor microenvironments and cell characteristics, and using nanomaterials as drug carriers via chemical and physical manners, enable the controlled delivery of drugs through exogenous (temperature, magnetic fields, ultrasound, and light and electric fields) or endogenous stimuli ( $\mathrm{pH}$, enzyme concentration, and redox). These approaches not only increase drug bioavailability and capacity to cross physical barriers, but also reduce the dosage to be used for treatment, consequently reducing the toxic side effects of the delivered drugs $[33,34]$. As shown in Figure 1, current methods for controlled drug delivery mainly include exogenous stimuli-responsive, endogenous stimuli-responsive, and multi-stimuli-responsive drug delivery. To make it more clear, the specific stimuli patterns was listed and illustrated in the next sections. Moreover, the corresponding examples of graphene-based nanomaterials for controlled drug delivery were also listed and showed in Table 1.

Table 1. Stimuli-responsive drug-delivery systems of graphene-based materials ${ }^{1}$.

\begin{tabular}{cccccc}
\hline Stimulus & Nanocarrier & Stabilizer & Drug & Targets & Reference \\
\hline Temperature & $\mathrm{GO} / \mathrm{PNP}$ & - & ADR & MC3T3-E1 cells & {$[35]$} \\
\hline Magnetic & Graphene $/ \mathrm{Fe}_{3} \mathrm{O}_{4}$ & - & Dox, PTXL & HeLa cells & {$[36]$} \\
\hline & $\mathrm{Au} @ \mathrm{GO}$ & - & Dox & HeLa cells & {$[37]$} \\
Light & $\mathrm{GO@Ag}$ & - & Dox, NGR & MCF-7 cells & {$[38]$} \\
& $\mathrm{GODs} / \mathrm{SiO}_{2} / \mathrm{Fe}_{3} \mathrm{O}_{4}$ & - & Dox & 4 T1 cells & {$[39]$} \\
& $\mathrm{GO} / \mathrm{CuS}$ & PEG & Dox & HeLa cells & {$[40]$} \\
Electric & $\mathrm{rGO}$ & PEG & Resveratrol & 4 T1 cells & {$[41]$} \\
\hline
\end{tabular}


Table 1. Cont.

\begin{tabular}{|c|c|c|c|c|c|}
\hline Stimulus & Nanocarrier & Stabilizer & Drug & Targets & Reference \\
\hline \multirow{11}{*}{$\mathrm{pH}$} & rGO & FA & Dox & MDA-MB 231 cells & [43] \\
\hline & GNS & starch & НСРТ & SW-620 cells & [44] \\
\hline & GQDs & RGD & Dox & DU-145, PC-3 celles & [45] \\
\hline & $\mathrm{CoFe}_{2} \mathrm{O}_{4} / \mathrm{GO}$ & - & Dox & HeLa cells & [46] \\
\hline & $\mathrm{GNS} / \mathrm{CNT} / \mathrm{Fe}_{3} \mathrm{O}_{4}$ & - & $5-\mathrm{FU}$ & HepG2 cells & [47] \\
\hline & GODs@MSN & - & Dox & A549 cells & [48] \\
\hline & GO & HA & Epirubicin & $\mathrm{B} 16 \mathrm{~F} 1$ cells & [49] \\
\hline & GO & HA & Dox & H22 hepatic cells & [50] \\
\hline & GO & $\mathrm{RC}$ & Dox & Hepatoma cells & [51] \\
\hline & GO & CMC, LA & Dox & SMMC-7721 cells & [52] \\
\hline & GdGODs & FA & Dox & HeLa, HepG2 cells & [53] \\
\hline \multirow{2}{*}{ Enzyme } & GO & PEG, peptide & Dox & A549 cells & [54] \\
\hline & GONR & DSPE-PEG & Lucanthone & U25 cells & [55] \\
\hline \multirow[b]{2}{*}{ Redox } & $\mathrm{GO} / \mathrm{Ag}$ & PEI & Dox & HeLa cells & [56] \\
\hline & GO & ALG-PEG & Dox & HepG2 cells & [57] \\
\hline \multirow{4}{*}{ Multi } & GO & HA & Dox & MDA-MB 231 cells & [58] \\
\hline & $\mathrm{rGO} / \mathrm{Au}$ & - & Dox & U87MG cells & [59] \\
\hline & $\mathrm{GO} / \mathrm{MSN}$ & - & Dox & MCF-7 cells & [60] \\
\hline & rGO & BPEI, PEG & Dox & PC-3 cells & [61] \\
\hline
\end{tabular}

${ }^{1}$ PTXL: paclitaxel; GO: graphene oxide; PNP: polymer nanoparticles; ADR: Adriamucin; NGR: Asn-Gly-Arg peptide; PPy: poly(pyrrole); DEX: dexamethasone; FA: folic acid; GNS: Graphene nanosheets; HCPT: Hydroxycamptothecin; GQDs: graphene quantum dots; RGD: arginine-glycine-aspartic acid; 5-FU: 5-fluorouracil; MSN: mesoporous silica nanoparticles; HA: hyaluronic acid; RC: Cyclic RGD/chitosan; CMC: carboxymethyl chitosan; LA: lactobionic acid; PEG-DSPE: 1,2-distearoyl-sn-glycero-3-phosphoethanolamine- $N$-[amino(polyethylene glycol]; GONR: graphene oxide nanoribbons; PEI: polyethylenimine; ALG-PEG: PEGylated alginate.



Figure 1. Ways of controlled drug delivery for various biomedical applications. AMF: alternating magnetic fields; NIR: near-infrared irradiation; DTT: dithiothreitol.

\subsection{Exogenous Stimuli-Responsive Drug Delivery}

Temperature-stimulated drug delivery. Two temperature-responsive controlled delivery systems currently exist. One is composed of temperature-sensitive nanogels (or composite particles), the volumes of which vary because of the changes in temperature. The drug delivery in this system is based on the changes of the volume of nanogels [62]. The other is composed of amphiphilic polymer 
micelles. In this system, the changes of temperature affect the solubility of temperature-sensitive block copolymers in solutions and cause the destruction of micellar structures [63]. These processes facilitate the drug delivery. For instance, Wang et al., reported that the drug loading and release of the thermos-sensitive graphene oxide-polymer nanoparticles hybrid could be controlled by adjusting temperature [35].

Magnetic field-stimulated drug delivery. Magnetic fields enable magnetic localization and local heating in vitro and in vivo. A constant external magnetic field can promote the aggregation of magnetic nanoparticles, which carry drugs at the location of the tumor. These magnetic nanoparticles exhibit hysteresis loss and/or Néel relaxation, and thus can serve as transducers to raise the temperature at a specific location within alternating magnetic fields (AMF), thus greatly speeding up the rate of drug release [64]. For example, the polymer stabilized $\mathrm{Fe}_{3} \mathrm{O}_{4}$-Graphene could rapidly release its loaded drug under an alternating magnetic field.

Unltrasound-stimulated drug delivery. Drugs can be delivered in large quantities from components that are subjected to continuous heating by ultrasound stimulation. Pulse ultrasound can be used for mechanical crushing, which undermine the stability of drug nanocarrier systems and significantly increases the amount of drug released within a short period [65].

Light-stimulated drug delivery. The most common methods of optically controlled drug delivery are based either on photochemical or photothermal reaction mechanisms. In general, photochemically controlled drug delivery could be achieved through photo-isomerization, photo-dimerization, light-induced fracture, or photo-bonding reactions of light-sensitive groups [66]. By contrast, photothermally controlled drug delivery is based on the light-heat transformation of nanoparticles after they absorb light. The transformation results in the increasement in local temperature and the amount of drugs delivered from the drug carrier. In addition, the thermal energy produced can kill cancer cells and enables photothermal ablation treatment. Nanomaterials that deliver drugs through heat stimulation generally contain gold nanoparticles, up-converted rare earth nanoparticles, and carbon nanotubes. For example, Shi et al. [38] and Bai et al. [40] discovered NIR-controlled Dox release behaviors from GO@Ag nanoparticles and GO/CuS nanocomposites, respectively.

Electric field-stimulated drug delivery. Electric fields can enable the directional release of drugs by affecting the binding force of drug molecules and nanocarriers. In particular, they cause the movement of charged molecules. Furthermore, additional transmembrane voltage can puncture cell membranes and thus increases the permeability of drugs [67]. For instance, Weaver and coworkers developed an electrically controlled drug delivery system that is based on GO nanosheets incorporated into a conducting polymer film, and found that the amount of drug released is linearly related to the time of voltage [42].

\subsection{Endogenous Stimuli-Responsive Drug Delivery}

pH-stimulated drug delivery. Owing to rapid breeding of tumor cells, veins near tumor cells cannot provide enough oxygen and nutrients for cell proliferation. Thus, anaerobic glycolysis occurs during cellular metabolism and produces a considerable amount of lactic acid, considerably decreasing the tumor $\mathrm{pH}$ value to below-normal levels. Therefore, the $\mathrm{pH}$ differences inside the body can be used to improve targeted drug delivery [68]. For example, HA-, RC-, and LA- functionalized GO were demonstrated exhibiting a $\mathrm{pH}$ sensitive anticancer drug release behavior [50-52].

Enzyme-stimuli drug delivery. Enzymes play an important role in cell regulation, and their type, activity, and concentration vary in different organelles and parts. Therefore, various activities and concentrations of enzymes can be used to deliver drugs to tumor tissues [69]. A common enzyme-controlled delivery mechanism includes the following processes: (i) degradation of peptide chains by proteases; (ii) degradation of polysaccharides by glycosidases; and, (iii) hydrolysation of phospholipid-containing block copolymers by lipases. Notably, the first process facilitates drug delivery in organelles. For instance, Jiang et al., developed a sequentially-functionalized GO as cellular protease-mediated programmed co-delivery system integrating membrane-related proteins 
and intracellular-functioning small-molecule drugs, this GO nanocarrier could efficiently release TRAIL to the sites of action through an enzyme stimuli manner [54].

Redox-stimulated drug delivery. The concentration of glutathione (GSH) in cells ranges from 2 to $10 \mathrm{mM}$, while its concentration in blood is $2-10 \mu \mathrm{M}$. Disulfide bonds in the blood and extracellular micro-oxidation environments are extremely stable. In cells, disulfide bonds undergo oxidation-reduction reactions with glutathione and can thus promote drug release through nanocarriers [70]. The concentration of glutathione in tumor cells is four times higher than in normal cells. Therefore, the amount of drug released in the tumor site is larger than those released in other sites and the release rate is faster. For example, Chen et al., demonstrated that the GO-Ag nanocomposite could efficiently release loaded Dox under GSH regulated environment [56]. In addition, oxidation responsiveness was also explored for triggered drug release in inflammatory tissues, which are characterized by an accumulation of reactive oxygen species (superoxide radicals, hydrogen peroxide, hydroxyl radicals, singlet oxygen). For instance, Wilson et al., reported that thioketal-based nanoparticles formulated with a reactive oxygen species-sensitive polymer could deliver small interfering RNAs to the sites of intestinal inflammation, thus realizing therapeutic levels of gene silencing after oral administration [71].

\subsection{Multi Stimuli-Responsive Drug Delivery}

Owing to the complexity of the human body and the location of tumors, practical research must include a variety of stimuli-responsive forms for drug delivery system design. These forms include $\mathrm{pH}$-redox, light— $\mathrm{pH}$, light—redox, ultrasound—enzyme, and temperature-magnetism collective stimuli-responsive forms [72-76]. For example, Song and coworkers reported that the as-prepared hybrid vesicle (rGO-loaded gold nanorod) not only exhibit a high loading capacity for DOX, but also could release the loaded DOX under a near-infrared irradiation (NIR) photothermal heating and intracellular acidic environment [59].

\section{Drug Delivery with Graphene-Based Nanomaterials}

In this section, we demonstrate recent studies on graphene-based nanocarriers for drug delivery and release. According to different types of graphene material modifier, four main categories (graphene-small molecule, graphene-nanoparticle, graphene-polymer, and graphene-biomacromolecule nanohybrids) are introduced and discussed.

\subsection{Graphene-Small Molecule Nanohybrids}

In the past five years, graphene and its derivatives have attracted considerable attention because of their excellent heat and electrical conductivity, biocompatibility, high specific surface area, and various surface oxygen-containing groups, and also shown considerable potential in drug delivery. For example, GO has been employed to deliver aromatic drug molecules into cells via $\pi-\pi$ stacking interactions $[43,44,77]$. Functional graphene quantum dots (GQDs) not only delivered the antitumor drug doxorubicin (DOX) into target cells, but can also monitor the cellular uptake and drug release process in real-time without the need of external dyes [45,53,78].

In the earlier work, related graphene-based carrier drugs were directly conjugated to graphene materials via $\pi-\pi$ stacking interactions. The advantage of this method is that the preparation process is simple and has high drug loading capacity, but the stability and biocompatibility of the final graphene-drug nanohybrids are hard to control. After that, some functional small molecules were employed to improve the stability and biocompatibility of nanocarriers. For instance, Zhou and co-workers discovered that the activity of Hypocrellin A (a photosensitive anticancer drug) could be enhanced significantly when 7-ethyl-10-hydroxycamptothecin and Hypocrellin A were co-loaded onto the surface of GO when compared with the modification of Hypocrellin A alone [77]. In vitro experimental results also showed that the photodynamic therapy effect has been greatly improved. In another study, Park et al., conjugated the reduced graphene oxide (rGO) with folic acid (FA) 
through noncovalent functionalization [43]. The as-prepared rGO/FA conjugate showed high dispersion stability in physiological media and enabled the accumulation of hydrophobic DOX. The in vitro results indicated that rGO/FA loaded DOX could specific target to MDA-MB 231 cells (human breast cancer cells), with an excellent drug-release efficiency $(>90 \%)$. Liu and co-workers prepared starch-functionalized graphene nanosheets (starch-GNS) via reducing exfoliated GO with soluble starch [44]. The as-prepared starch-GNS showed good biocompatibility and a high drug loading capacity. The experimental data indicated that $150 \mu \mathrm{g}$ of starch-GNS can load $12 \mu \mathrm{g}$ of hydroxycamptothecine by physisorption.

Small molecule-modified GQDs could also be utilized for simultaneous drug delivery cellular imaging. For example, Qiu et al. [45] and Wang et al. [78] modified GQDs with arginine-glycine-aspartic acid (RGD) and FA, respectively (Figure 2a,b). The DOX loaded RGD- or FA-modified GQDs could not only deliver drugs to target cells effectively, but also monitor the process of cellular uptake the drug in real-time without employing external dyes, as shown in Figure 2c,d. In another case, Huang and co-workers developed multifunctional paramagnetic GQDs (folate-GdGQDs) for simultaneous dual-modality bioimaging and tutor targeted drug delivery [53]. The synthetic folate-GdGQDs exhibited a strong therapeutic activity by loading DOX though $\pi-\pi$ stacking and hydrophobic interactions, and the fabricated nanocarriers could release about $80 \%$ of DOX at $\mathrm{pH}$ 5.0 after $48 \mathrm{~h}$. Moreover, the folate-GdGQDs also showed an excellent biocompatibility and good targeting ability for noninvasive cancer diagnosis with $T_{1}$-weighted magnetic resonance (MR) and fluorescence imaging.

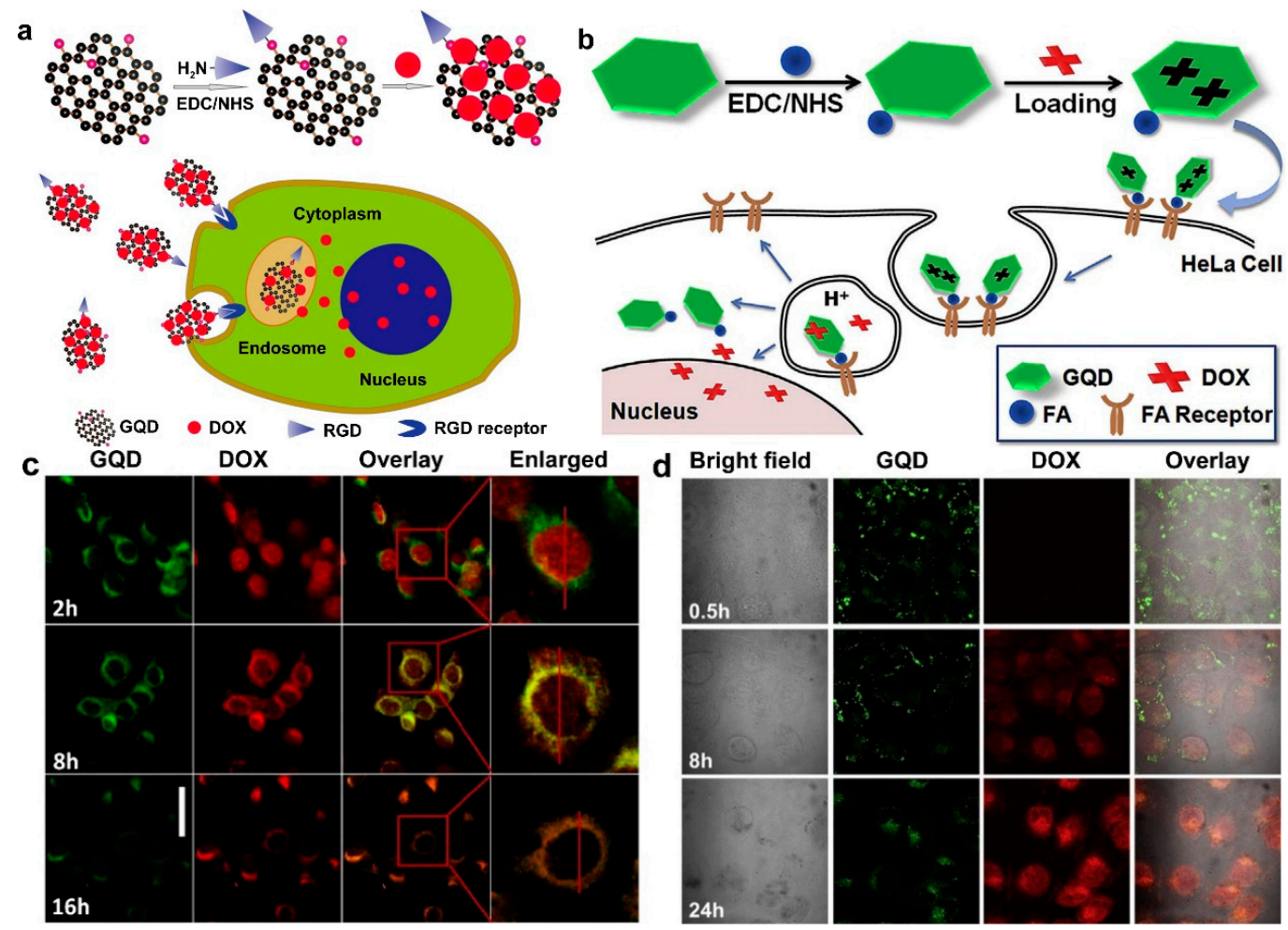

Figure 2. Small molecule-modified graphene for drug delivery. (a) Schematic illustration of the geometry of multifunctional graphene quantum dots (GQD) for targeted delivery of drug doxorubicin (DOX) and their interactions with cancer cells; (b) Schematic of the fabricated DOX- folic acid (FA)-GQD nanoassembly for DOX delivery into target cells; (c) DU-145 cells incubated with DOXarginine-glycine-aspartic acid (RGD)-GQD; and, (d) Confocal laer scaning microscope images of HeLa cells incubated with DOX-FA-GQD. EDC: $N$-(3-Dimethylaminopropyl)- $N$ '-ethylcarbodiimide; NHS: N-Hydroxysuccinimide. Part $(\mathbf{a}, \mathbf{c})$ are reproduced with permission from [45]. Copyright Dovepress, 2015. Part (b,d) are reproduced with permission from [78]. Copyright Elsevier, 2014. 


\subsection{Graphene-Nanoparticle Nanohybrids}

Chemically synthesized GO presents many oxygen-containing groups, such as hydroxyl, carboxylic, and epoxide groups, and therefore various inorganic nanoparticles have been anchored onto the surface of GO or rGO to offer additional optical and magnetic properties. When hybridized with gold or silver nanoparticles, graphene-based nanocarriers can serve as active materials for surface enhanced Raman scattering (SERS) experiments for monitoring the process of drug delivery $[37,38,56,59,79]$. When hybridized with magnetic nanoparticles, graphene-based nanomaterials can be used as magnetic materials for MR imaging [36,39,46,47,80].

Metallic nanoparticles could be used for simultaneous drug delivery and bioimaging of cells. For instance, Ma and co-workers fabricated three-dimensional (3D) spherical nanohybrids by wrapping GO onto gold nanoparticles (Au-GO) through a simple one-step synthesis [37]. The as-prepared Au-GO nanohybrid can not only be used for intracellular Raman imaging in HeLa cells, but can also be exploited to deliver DOX into cancer cells for chemotherapy, as shown in Figure 3. Wang and co-workers conjugated Au nanostars onto the surface of rGO through a seed-mediated growth method, and the synthesized Au@rGO nanocomposites showed an improved colloidal stability, and sensitive SERS response toward Raman-active molecules [79]. These nanocomposites can be used as an active SERS material for anticancer DOX loading and pH-dependent release. In another case, Song et al., developed a hybrid rGO-loaded ultra-small plasmonic Au nanorod vesicle $(\sim 65 \mathrm{~nm})$. The hybrid vesicle exhibited high loading capacity for DOX (65\%), and also showed excellent photothermal effect and photoacoustic performance when irradiated with a near infrared laser [59]. Similarly, GO-loaded Ag nanoparticles can also monitor the intracellular release behavior [38,56]. For instance, Shi et al., synthesized a GO@Ag nanocomposite by the chemical deposition of Ag nanoparticles onto the GO surface via a hydrothermal reaction [38]. The fabricated GO@Ag-DOX nanohybrids could serve not only as a near infrared controlled drug releasing delivery system, but also as both X-ray imaging and tumor photothermal ablation agents.

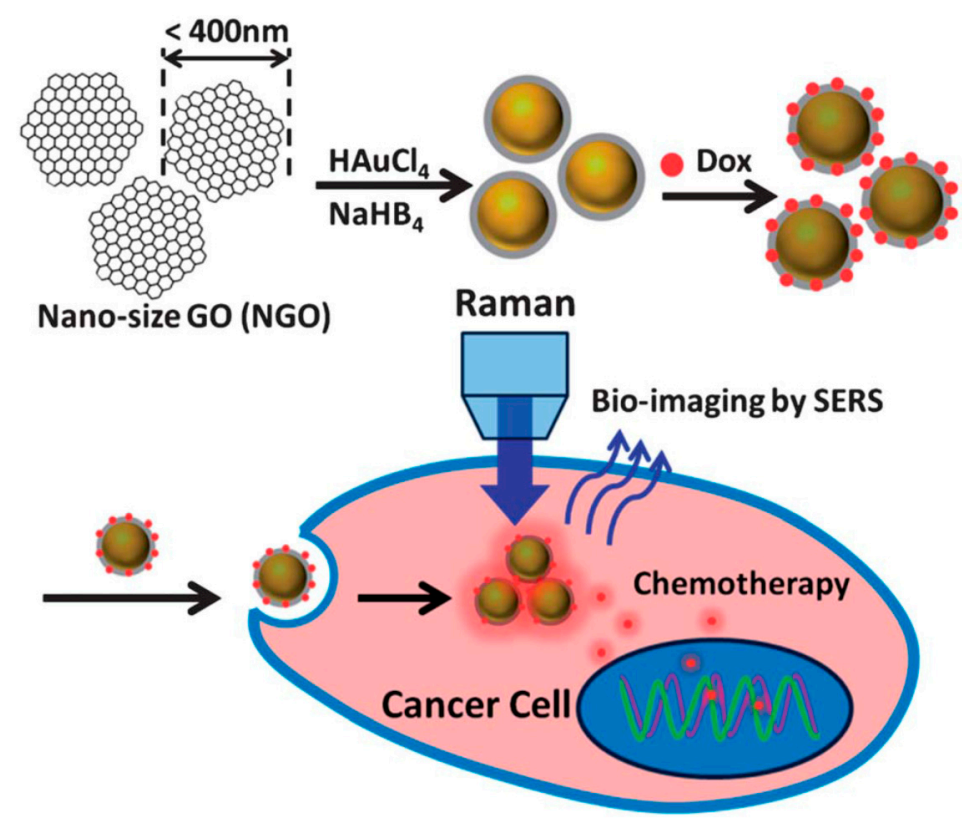

Figure 3. Schematic illustration of surface enhanced Raman scattering (SERS) based imaging and anticancer drug delivery by using Au@GO. Reproduced with permission from [79]. Copyright Royal Society of Chemistry, 2014.

Magnetic metallic oxide nanoparticles could be linked with graphene for stimulation-responsive drug delivery. For instance, Wang et al., modified magnetic $\mathrm{Fe}_{3} \mathrm{O}_{4}$ nanoparticles onto the surface of GO 
nanosheets via an inverse co-precipitation method [80]. The as-prepared $\mathrm{Fe}_{3} \mathrm{O}_{4} / \mathrm{GO}$ nanocomposites exhibited superparamagnetic property with the saturation magnetization of $63.3 \mathrm{emu} \mathrm{g}^{-1}$ and significant negative contrast enhancement effect in vitro. The nanocarrier also showed a high loading capacity for 5-fluorouracil $\left(0.37 \mathrm{mg} \mathrm{mg}^{-1}\right)$, and the drug release can be controlled by the environment's $\mathrm{pH}$. In order to achieve the control of the size and loading amount of the magnetic nanoparticles, they further developed $\mathrm{CoFe}_{2} \mathrm{O}_{4} / \mathrm{GO}$ nanocomposites by means of a facile sonochemical method [46]. The obtained $\mathrm{CoFe}_{2} \mathrm{O}_{4} / \mathrm{GO}$ nanohybrids showed superparamagnetic behavior $\left(38.7 \mathrm{emu} \mathrm{g}^{-1}\right)$, high hydrophility, and ultralow cytotoxicity. Most importantly, the DOX loading capacity of the formed nanocomposites reached $1.08 \mathrm{mg} \mathrm{mg}^{-1}$.

With a complex nanohybrid system, the delivery of drugs can also be controlled. Fan et al., synthesized graphene nanosheet-carbon nanotube-iron oxide nanoparticle nanocomposites $\left(\mathrm{GN}-\mathrm{CNT}-\mathrm{Fe}_{3} \mathrm{O}_{4}\right)$ by a green and facile approach. The as-prepared $\mathrm{GN}-\mathrm{CNT}-\mathrm{Fe}_{3} \mathrm{O}_{4}$ nanohybrids exhibited superparamagnetic behavior $\left(19.8 \mathrm{emu} \mathrm{g}^{-1}\right)$, good biocompatibility for Chang liver cells, high loading capacity for 5-fluorouracil $\left(0.27 \mathrm{mg} \mathrm{mg}^{-1}\right)$, and possessed a $\mathrm{pH}$-activated release profile [47]. Swain et al., synthesized polymer-stabilized iron oxide-graphene (PIG) nanocomposites via a one-step solvothermal process [36]. The as-prepared PIG exhibited high colloidal stability and biocompatibility, and could efficiently bind with both hydrophilic and hydrophobic drugs. The drug loading efficiency of PIG is $\sim 87 \%$ for DOX and $\sim 91 \%$ for paclitaxel, respectively.

Yao and co-workers developed a multifunctional platform for synergistic therapy with controlled drug release, magnetic hyperthermia, and photothermal therapy [39], which used GQDs as caps and local photothermal generators and magnetic mesoporous silica nanoparticles (MMSN) as drug carriers and magnetic thermoseeds (Figure 4). The obtained MMSN/GQD could effectively produce heat under an AMF and/or near infrared irradiation. The combined chemo-magnetic hyperthermia therapy or chemo-photothermal therapy showed a higher efficiency than chemotherapy, magnetic hyperthermia, or photothermal therapy alone.

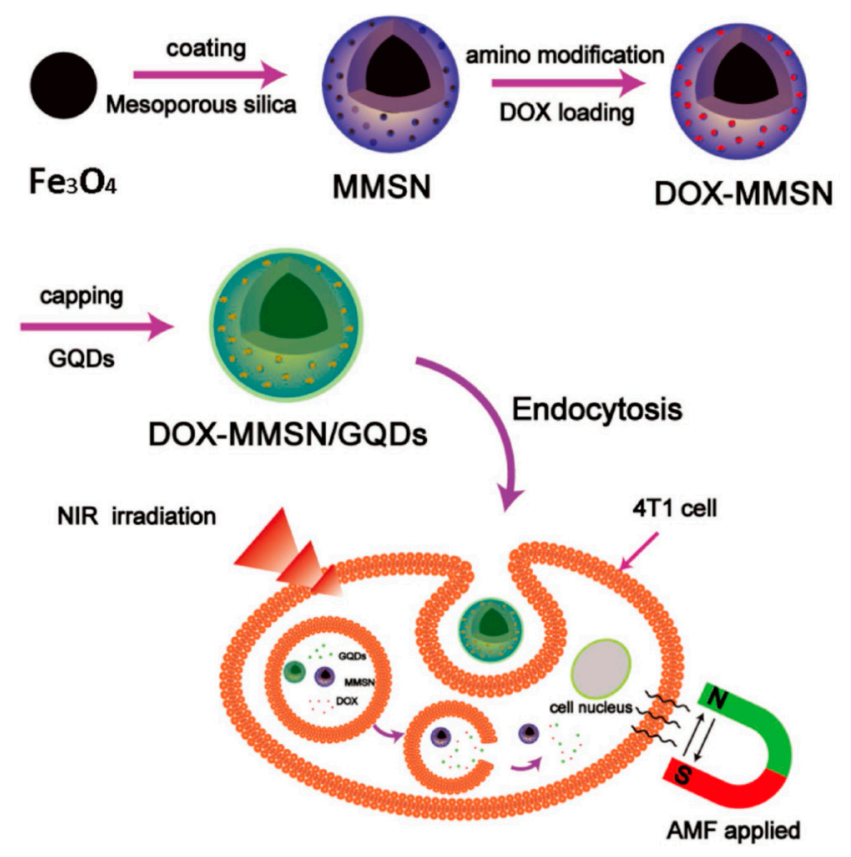

Figure 4. Schematic illustration of the preparation of DOX- magnetic mesoporous silica nanoparticles (MMSN)/GQD nanohybrids and its controlled drug release and photothermal therapy mechanism. Reproduced with permission from [39]. Copyright Wiley-VCH, 2017.

Nanoparticle-modified GQDs could be also used as a potential drug delivery platform. For example, Chen and coworkers functionalized fluorescent GQDs onto mesoporous silica 
nanoparticles (MSN) via acid-cleavable acetal bonds. The GQD@MSN nanohybrid not only can effectively load and release DOX, but can also track the drug delivery process in vitro [48]. Tang et al., developed an aptamer-targeting photoresponsive drug delivery system by non-covalent assembly of Cy5.5-AS1411 aptamer conjugate on the surface of GO wrapped DOX-loaded MSN (MSN-DOX@GO-APT) for light-mediated drug release and aptamer-targeted cancer therapy [60]. The in vitro experimental results indicated that the synergism of chemo- and photothermal therapy in a single MSN-DOX@GO-APT platform has high performance to kill cancer cells than monotherapies. Bai and coworkers developed a multifunctional drug delivery system by combining GO with low cytotoxic, high photothermal conversion efficient $\mathrm{CuS}$ nanoparticles. The as-prepared nanocomposite exhibited a high loading efficiency $\left(900 \mu \mathrm{g} \mathrm{mg}^{-1}\right)$ and $\mathrm{pH}$-responsive DOX release under near infrared laser irradiation [40].

\subsection{Graphene-Polymer Nanohybrids}

A lot of polymers could be utilized to modify graphene for drug delivery applications. Ten years ago, Liu et al., first discovered that polyethylene glycol (PEG)-functionalized GO can be used as a novel drug nanocarrier to load anti-cancer drugs via non-covalent physisorption with in vitro cellular uptake capacity [17]. After that, graphene-polymer nanocomposites have been widely explored as drug carriers in recent years. For instance, Kim and co-workers developed a photothermally triggered drug delivery system by modifying $\mathrm{rGO}$ with branched polyethylenimine (BPEI) and PEG [61]. The as-prepared PEG-BPEI-rGO nanocomposite exhibited high water stability and dramatically enhanced DOX loading efficiency. Chen et al., developed one-pot green reduction and PEGylation of GO to construct a high-efficiency drug loading and photothermally triggered drug delivery system [41]. The as-prepared PEG-GO nanohybrids showed better water stability, high near infrared irradiation absorbance, and $\sim 2$-fold increment in resveratrol loading efficiency over the unreduced ones. Zhao and coworkers modified GO with biocompatible PEGylated alginate brushes (PEG-ALG-GO) via the disulfide bridge bond [57]. The obtained nanoscale 3D biocompatible, reduction-responsive PEG-ALG-GO nanohybrids showed efficiently loading $(97.0 \pm 3 \%)$ and releasing $(30.6 \%)$ of DOX.

Other biocompatible polymers, like polyethylenimine (PEI) and hyaluronic acid (HA), also showed high potentials to modify graphene for drug delivery. For example, Yan et al., used PEI-GO as a nanocarrier, the as-prepared PEI-GO nanohybrids showed high stability in both water and physiological solutions, and combined the functionalities of the nanocrystals and PEI-GO, such as luminescence, superparamagnetism, and drug delivery capacity (with a superior loading capacity of $100 \mathrm{wt}$ \% for DOX) [81]. In another study, Jung et al., prepared HA-GO nanohybrids (Figure 5) by conjugating GO nanosheets with 38\% hexanethylenediamine (HMDA)-modified HA for targeting specific delivery of epirubicin via HA receptor mediated endocytosis [49]. The loading amount of epirubicin on HA-GO increased significantly with an increasing of the $\mathrm{pH}$ of epirubicin solutions, which is beneficial for the release of drug in the acidic environment of tumor (Figure 6). In other cases, HA-GO nanohybrids have been utilized for the $\mathrm{pH}$-responsive delivery of DOX for tumor therapy $[50,82]$. 

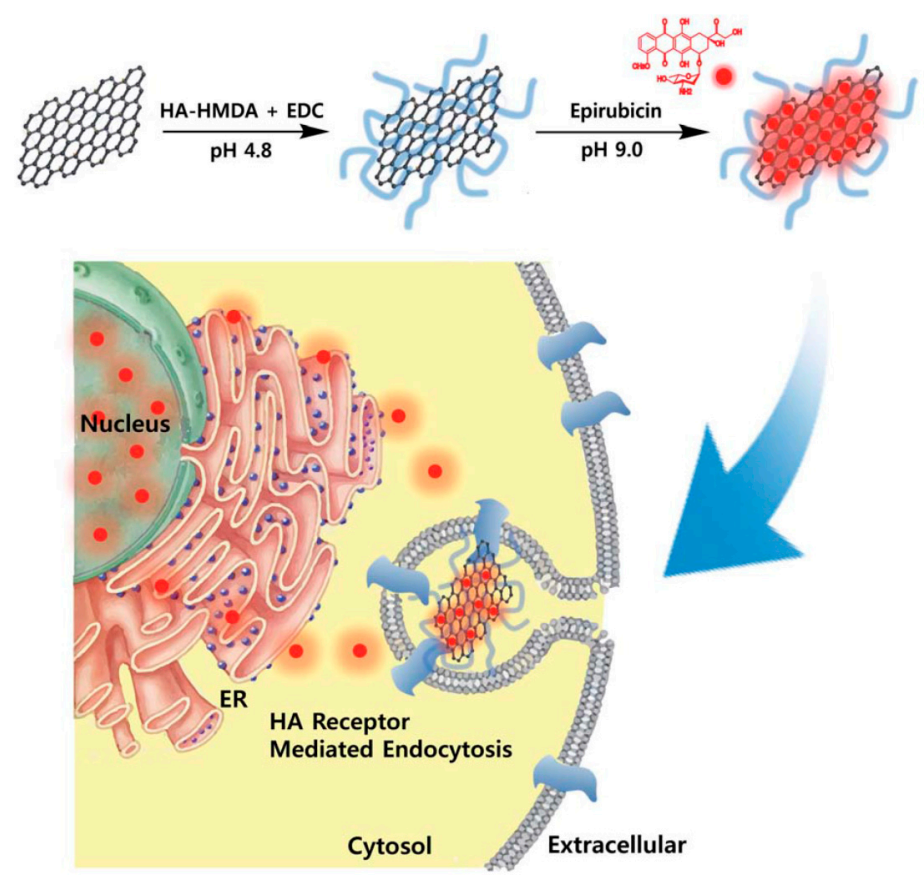

Figure 5. The preparation process of epirubicin/NGO- hyaluronic acid (HA) nanohybrid and the mechanism of drug controlled release. NGO: nanoscale gaphene oxide. Reproduced with permission from [49]. Copyright Royal Society of Chemistry, 2014.
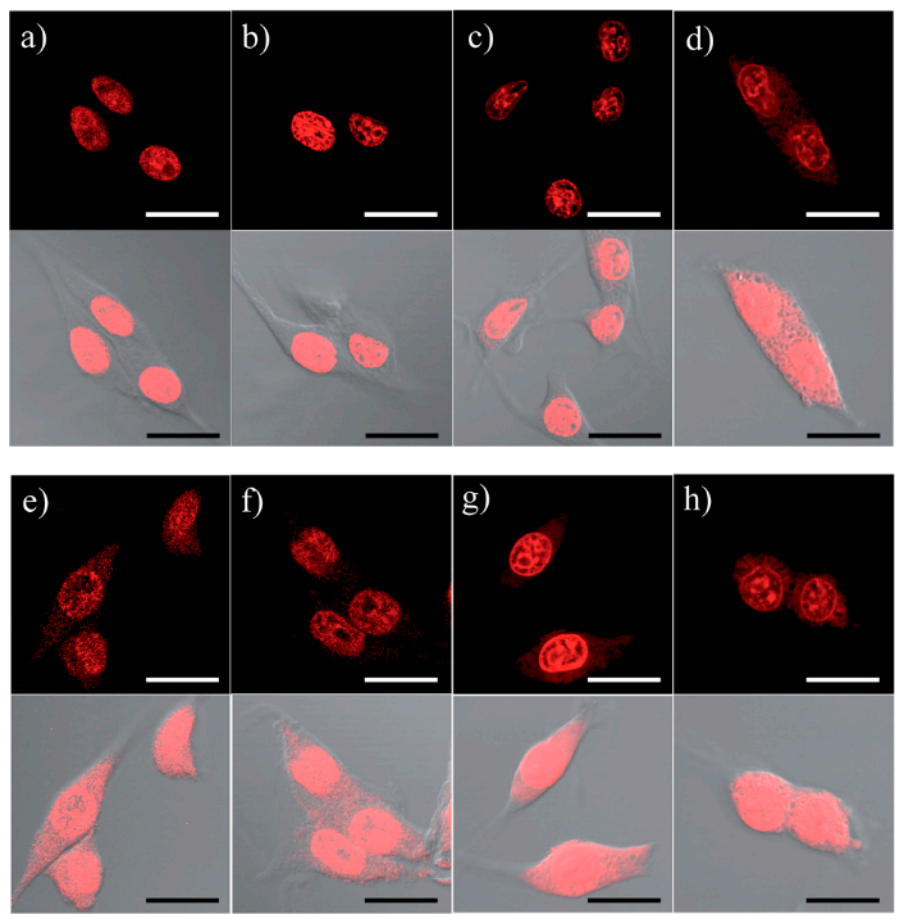

Figure 6. Confical laser scanning microscopic images of B16F1 cells showing the different drug delivery patterns after treatment with epirubicin for (a) $10 \mathrm{~min}$, (b) $1 \mathrm{~h}$, (c) $12 \mathrm{~h}$, (d) $24 \mathrm{~h}$ and with eqirubicin/NGO-HA complex for (e) $10 \mathrm{~min}$, (f) $1 \mathrm{~h}$, (g) $12 \mathrm{~h}$, (h) $24 \mathrm{~h}$, respectively. Reproduced with permission from [49]. Copyright Royal Society of Chemistry, 2014.

Stimulation-responsive polymers could also be utilized to modify graphene for controlled drug delivery. With the aid of lower critical solution temperature of poly( $N$-isopropylacrylamide) 
(PNIPAM), Wang et al., synthesized PNIPAM-poly(ethylene oxide)-based polymer nanoparticles (PNPs) by free radical polymerization reaction and then assembled PNPs onto the 1-pyrenebutyric acid $N$-hydroxysuccinimide ester functionalized GO nanosheets [35], as shown in Figure 7. The obtained thermo-sensitive PNPs-GO nanohybrid had $\sim 87 \%$ of loading efficiency and $13-22 \%$ of release efficiency for adriamycin (ADR). This new nanohybrid showed great potential in in vivo applications, for instance to kill target cancer cells via modification with specific antibodies. In another case, Weaver and coworkers explored an electrically stimulated drug delivery nanocomposite composed of GO that was deposited inside a conducting polymer scaffold [42]. The amount of drug release of the nanocomposite was linear with the dosage of electrical stimulation, and in vitro results also showed that the released drug retains its bioactivity and no toxic byproducts leach from the film during electrical stimulation. Wang et al., developed an innovative multifunctional $\mathrm{pH}$-responsive drug delivery system for hepatocellular carcinoma-targeted therapy and imaging by coating DOX-GO with cyclic RGD-modified chitosan [51]. The obtained nanohybrids exhibited higher loading capacity for DOX $\left(1.0 \mathrm{mg} \mathrm{mg}^{-1}\right)$, $\mathrm{pH}$-responsive behavior, and potential application in hepatocellular carcinoma therapy.
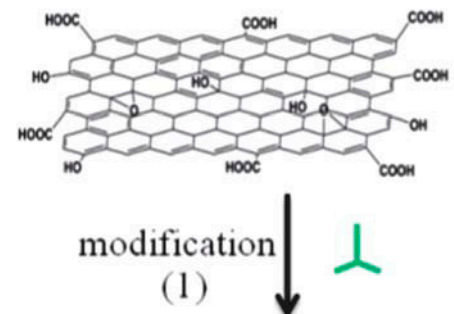

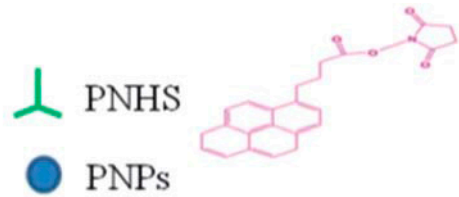

- $\mathrm{ADR}$

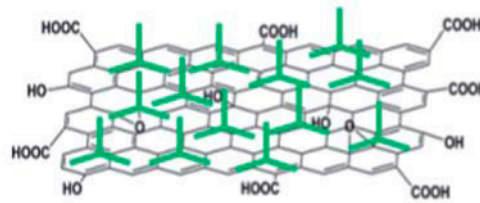

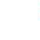
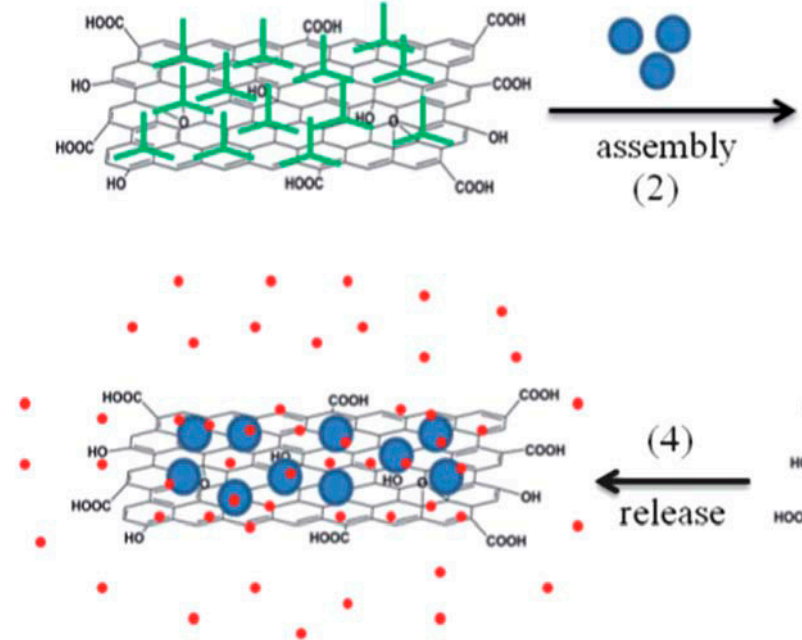

(2)
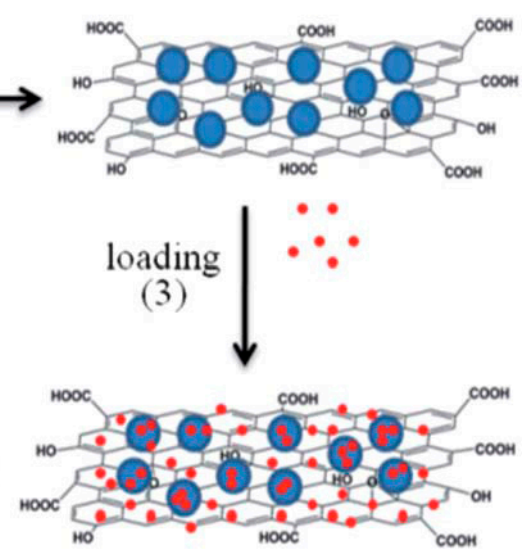

Figure 7. Schematic illustration of the synthesis of thermo-responsive graphene (GO)-polymer nanoparticles (PNPs) nanohybrids for loading and release of adriamycin (ADR). Reproduced with permission from [35]. Copyright Royal Society of Chemistry, 2014.

Block co-polymers have exhibited potential to modify graphene for controlled and high performance drug delivery. In a recent study, Chowdhurg et al., coated GO nanoribbons with an amphiphilic block polymer, 1,2-distearoyl-sn-glycero-3-phosphoethanolamine- $N$-[amino(polyethylene glycol)], and found that the fabricated nanohybrids could efficiently load and deliver lucanthone to the glioblastoma multiformae cell line U251 [55]. In another study, Song et al., synthesized a graphene/tri-block copolymer nanocomposite by coating graphene with drug-loaded tri-block copolymer via $\pi-\pi$ stacking interaction [83]. The as-prepared nanocomposites exhibited a well-dispersed stability in aqueous medium and dual release behaviors either under acid environment or via biodegradation of the predesigned disulfide bonds. 
Furthermore, graphene-polymer nanohybrid-based multi-systems have been used for drug delivery application. For instance, Jiang and co-workers [54] modified GO with PEG linker and tumor-necrosis-factor-related apoptosis-inducing ligand (TRAIL) by step-by-step site-specific modifications, as shown in Figure 8a. The designed nanocarriers could efficiently release TRAIL and DOX to their distinct sites of action separately, in a site-specific manner (Figure 8b). In addition, this two-dimensional (2D) nanocarrier also showed great potential in programmed-release therapeutics capability. Recently, Yang et al., modified GO with carboxymethyl chitosan (CMC), HA, and fluorescein isothiocyanate (FI) to enhance the efficiency and specificity of anticancer drug delivery [84]. The obtained HA-FI-CMC-GO exhibited a high loading capacity for DOX (95\%) and rapid release rate under tumor cell microenvironment of $\mathrm{pH}$ 5.8. In addition, the DOX-loaded HA-FI-CMC-GO could specifically target cancer cells and effectively inhibit the growth of cancer cells. In another case, Pan et al., functionalized GO with CMC, FI, lactobionic acid (LA), and acylation (Ac) for delivering DOX to liver cancers [52]. The as-prepared Ac-LA-FI-CMC-GO had high DOX loading content and efficiency $(>96 \%)$ and $\mathrm{pH}$-sensitive release.

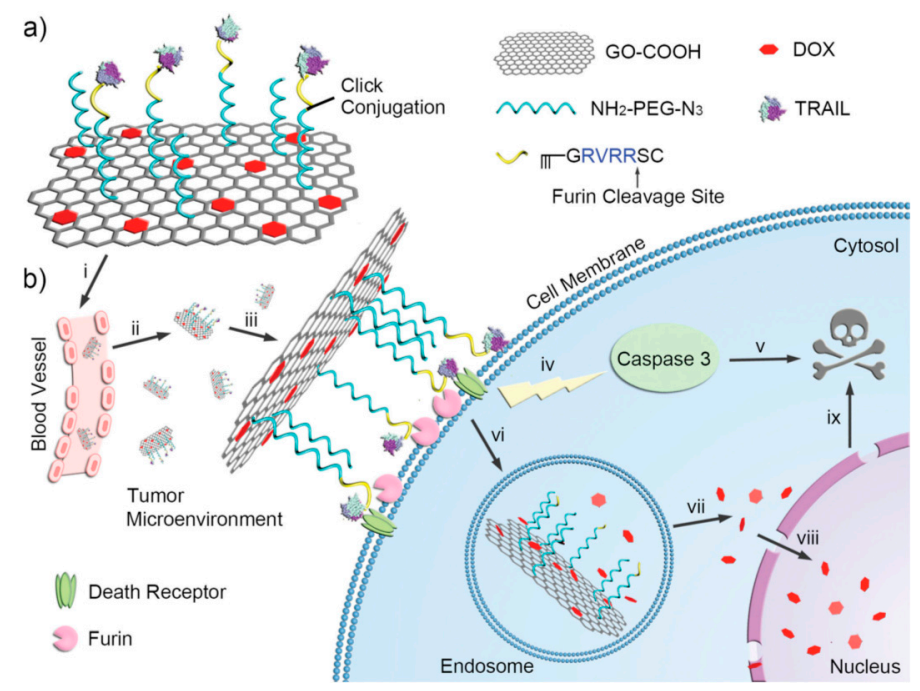

Figure 8. (a) Main components of tumor-necrosis-factor-related apoptosis-inducing ligand (TRAIL)/DOX-FGO; (b) Site-specific delivery of TRAIL to cell membrance and DOX to nuclei for enhanced synergist cancer treatment. Reproduced with permission from [54]. Copyright Wiley-VCH, 2014.

\subsection{Graphene-Biomacromolecule Nanohybrids}

Due to their rich functions, good biocompatibility, and fine stability in human body environment, biomacromolecules like protein, peptide, DNA, and others, attracted more attentions in drug delivery in recent years. Hu et al. [85] synthesized photo-responsive protein-graphene-protein (PGP) capsules by anchoring rGO on one-component protein shell through a double emulsion method (Figure 9a). The PGP capsules showed good biocompatibility and high loading capacity for DOX $\left(9.43 \mu \mathrm{mol} \mathrm{g}^{-1}\right)$. The fabricated capsules could eradicate subcutaneous tumors in 10 days following a single 5 min near-infrared irradiation (NIR) without distal damage. It was found that with the drug loading onto the PGP capsules, drugs could be released from PGP by NIR therapy, and the live cancer cells could be killed effectively, as shown in Figure 9b. 


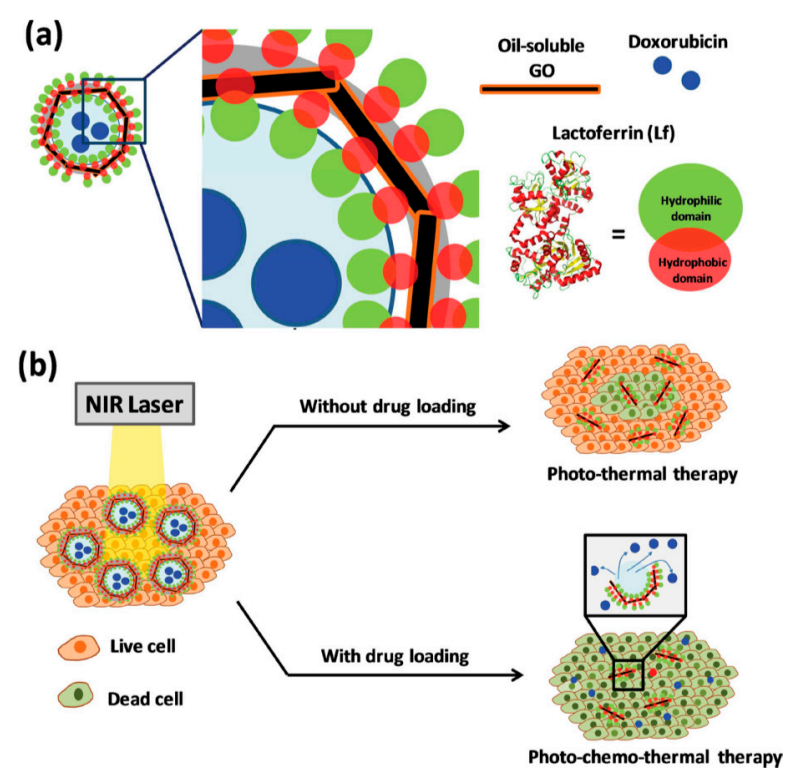

Figure 9. Schematic illustration of (a) core-shell protein-graphene-protein (PGP) capsules encapsulating hydrophilic doxorubicin; and (b) the mechanism of cancer therapy of PGP capsules under near-infrared irradiation (NIR). Reproduced with permission from [85], Copyright Wiley-VCH, 2014.

Wang and co-workers conjugated GO nanosheets with chlorotoxin for glioma therapy [86]. The maximum loading of DOX on target peptide chlorotoxin-conjugated GO (CTX-GO) is $570 \mathrm{mg} \mathrm{g}^{-1}$. The DOX-loaded CTX-GO could release DOX under the tumor $\mathrm{pH}$ microenvironment and kill more glioma cells than both free DOX and DOX-loaded GO. Mo et al., functionalized GO with two single-stranded DNA molecules and adenosine-5' ${ }^{\prime}$-triphosphate (ATP) for ATP-responsive anticancer drug delivery [27]. The conjugated ATP aptamer not only effectively inhibited the DOX release from GO nanosheets, but also promoted the release of DOX in a high ATP concentration environment, such as cytosol, when compared with that in the ATP-deficient fluid. Wu and co-workers developed a peptide-GO hybrid hydrogel for DOX delivery and pulse-triggered release [87]. In the prepared hybrid hydrogel, the peptide was linked with GO by $\pi-\pi$ interaction and the peptide molecules were connected either by hydrogen bonds or direct covalent cross-linking. The strong interactions (e.g., covalent cross-linking) could serve as permanent cross-links that warrant the high stability of the hydrogel, whereas the weak interactions (e.g., $\pi-\pi$ interaction) could be temporarily broken upon external triggering. Therefore, the created peptide-GO hydrogel possessed high mechanic and chemical stability and were suitable for being triggered by NIR for controlled drug delivery and therapy.

\section{Conclusions and Perspectives}

In summary, we demonstrated various ways of drug delivery with different nanomaterials and the recent typical studies on the synthesis of graphene-based nanomaterials for controlled drug delivery. It is clear that graphene-based nanomaterials play important roles in improving the drug loading and release performances. In addition, when some other nanoscale building blocks, like small molecules, nanoparticles, polymers, DNA, proteins, and peptides were modified onto graphene or GO, both biological properties and drug delivery function could be enhanced to a great extent. Due to the unique structure (2D, monolayer) and properties (high stability, good conductivity, easy modification) of graphene, the facile synthesis of novel graphene-based nanomaterials will extend biomedical applications in the future.

In the last years, a large amount of studies on the drug delivery application with graphene-based nanomaterials have been reported, but there are still some aspects that should be further focused on. First, more synthesis methods of monolayer graphene (GO and RGO) and the subsequent biomolecular 
modifications with proteins, peptides, DNA, and others could be developed. The monolayered graphene-based bio-nanohybrids will show interesting results for drug delivery, biosensing, and tissue engineering. Second, the long-period biocompatibility and cellular toxicity of graphene-based nanomaterials should be investigated. Third, the biological interactions between graphene and cells, tissues, or organs should be studied in depth to understand the cellular uptake mechanisms, such as Li et al., and Duch et al., found that the pristine graphene and GO can induce cytotoxicity through the depletion of the mitochondrial membrane potential and the increase of intracellular reactive oxygen species, and then trigger apoptosis by activation of the mitochondrial pathway [88,89], respectively. Finally, as most of studies are currently focused on the delivery of drug for cancer cells, it is possible to utilize graphene-based nanomaterials for the detection and therapy of other diseases such as Parkinson's, Alzheimer's, HIV, and others. For example, previously Yang and co-workers have reported that graphene could destruct the formation of amyloid fibrils [90], which provides a potential idea for designing graphene-based anti-Alzheimer's drugs.

Acknowledgments: Zhuqing Wang thanks the financial supports from the national natural science foundation of China (No. 21407004) and natural science foundation of Anhui province (Nos. 1508085QB48, KJ2017A345). Gang Wei and Lucio Colombi Ciacchi acknowledge the supports from the Deutsche Forschungsgemeinschaft (DFG) under grants WE 5837/1-1 (Gang Wei) and CI 144/2 (Lucio Colombi Ciacchi).

Author Contributions: Gang Wei and Lucio Colombi Ciacchi proposed and organized the contents of this review. Zhuqing Wang and Gang Wei wrote the paper. Gang Wei and Lucio Colombi Ciacchi made revisions on the manuscript.

Conflicts of Interest: The authors declare no conflict of interest. The founding sponsors had no role in the design of the study; in the collection, analyses, or interpretation of data; in the writing of the manuscript, and in the decision to publish the results.

\section{References}

1. Hubbell, J.A.; Chilkoti, A. Nanomaterials for drug delivery. Science 2012, 337, 303-305. [CrossRef] [PubMed]

2. Keles, E.; Song, Y.; Du, D.; Dong, W.J.; Lin, Y.H. Recent progress in nanomaterials for gene delivery applications. Biomater. Sci. 2016, 4, 1291-1309. [CrossRef] [PubMed]

3. Cho, K.J.; Wang, X.; Nie, S.M.; Chen, Z.; Shin, D.M. Therapeutic nanoparticles for drug delivery in cancer. Clin. Cancer Res. 2008, 14, 1310-1316. [CrossRef] [PubMed]

4. Patri, A.K.; Majoros, I.J.; Baker, J.R. Dendritic polymer macromolecular carriers for drug delivery. Curr. Opin. Chem. Biol. 2002, 6, 466-471. [CrossRef]

5. Schmaljohann, D. Thermo- and ph-responsive polymers in drug delivery. Adv. Drug Deliv. Rev. 2006, 58, 1655-1670. [CrossRef] [PubMed]

6. Wang, H.X.; Li, J.F.; Zhang, X.Y.; Ouyang, Z.F.; Li, Q.; Su, Z.Q.; Wei, G. Synthesis, characterization and drug release application of carbon nanotube-polymer nanosphere composites. RSC Adv. 2013, 3, 9304-9310. [CrossRef]

7. Vallet-Regi, M.; Balas, F.; Arcos, D. Mesoporous materials for drug delivery. Angew. Chem. Int. Ed. 2007, 46, 7548-7558. [CrossRef] [PubMed]

8. Novoselov, K.S.; Geim, A.K.; Morozov, S.V.; Jiang, D.; Zhang, Y.; Dubonos, S.V.; Grigorieva, I.V.; Firsov, A.A. Electric field effect in atomically thin carbon films. Science 2004, 306, 666-669. [CrossRef] [PubMed]

9. Zhang, B.M.; Wang, Y.; Zhai, G.X. Biomedical applications of the graphene-based materials. Mater. Sci. Eng. C 2016, 61, 953-964. [CrossRef] [PubMed]

10. Chung, C.; Kim, Y.K.; Shin, D.; Ryoo, S.R.; Hong, B.H.; Min, D.H. Biomedical applications of graphene and graphene oxide. Acc. Chem. Res. 2013, 46, 2211-2224. [CrossRef] [PubMed]

11. Su, Z.Q.; Shen, H.Y.; Wang, H.X.; Wang, J.H.; Li, J.F.; Nienhaus, G.U.; Shang, L.; Wei, G. Motif-designed peptide nanofibers decorated with graphene quantum dots for simultaneous targeting and imaging of tumor cells. Adv. Funct. Mater. 2015, 25, 5472-5478. [CrossRef]

12. Wang, J.H.; Ouyang, Z.F.; Ren, Z.W.; Li, J.F.; Zhang, P.P.; Wei, G.; Su, Z.Q. Self-assembled peptide nanofibers on graphene oxide as a novel nanohybrid for biomimetic mineralization of hydroxyapatite. Carbon 2015, 89, 20-30. [CrossRef] 
13. Zhang, P.P.; Wang, H.X.; Zhang, X.Y.; Xu, W.; Li, Y.; Li, Q.; Wei, G.; Su, Z.Q. Graphene film doped with silver nanoparticles: Self-assembly formation, structural characterizations, antibacterial ability, and biocompatibility. Biomater. Sci. 2015, 3, 852-860. [CrossRef] [PubMed]

14. Sun, X.M.; Liu, Z.; Welsher, K.; Robinson, J.T.; Goodwin, A.; Zaric, S.; Dai, H.J. Nano-graphene oxide for cellular imaging and drug delivery. Nano Res. 2008, 1, 203-212. [CrossRef] [PubMed]

15. Wang, C.S.; Li, J.Y.; Amatore, C.; Chen, Y.; Jiang, H.; Wang, X.M. Gold nanoclusters and graphene nanocomposites for drug delivery and imaging of cancer cells. Angew. Chem. Int. Ed. 2011, 50, 11644-11648. [CrossRef] [PubMed]

16. Depan, D.; Shah, J.; Misra, R.D.K. Controlled release of drug from folate-decorated and graphene mediated drug delivery system: Synthesis, loading efficiency, and drug release response. Mater. Sci. Eng. C 2011, 31, 1305-1312. [CrossRef]

17. Liu, Z.; Robinson, J.T.; Sun, X.M.; Dai, H.J. Pegylated nanographene oxide for delivery of water-insoluble cancer drugs. J. Am. Chem. Soc. 2008, 130, 10876-10877. [CrossRef] [PubMed]

18. Zhao, X.J.; Li, Y.; Wang, J.H.; Ouyang, Z.F.; Li, J.F.; Wei, G.; Su, Z.Q. Interactive oxidation-reduction reaction for the in situ synthesis of graphene-phenol formaldehyde composites with enhanced properties. ACS Appl. Mater. Interfaces 2014, 6, 4254-4263. [CrossRef] [PubMed]

19. Zhang, X.Y.; Yin, J.L.; Peng, C.; Hu, W.Q.; Zhu, Z.Y.; Li, W.X.; Fan, C.H.; Huang, Q. Distribution and biocompatibility studies of graphene oxide in mice after intravenous administration. Carbon 2011, 49, 986-995. [CrossRef]

20. Yang, K.; Wan, J.M.; Zhang, S.A.; Zhang, Y.J.; Lee, S.T.; Liu, Z.A. In vivo pharmacokinetics, long-term biodistribution, and toxicology of pegylated graphene in mice. ACS Nano 2011, 5, 516-522. [CrossRef] [PubMed]

21. Li, D.P.; Zhang, W.S.; Yu, X.Q.; Wang, Z.P.; Su, Z.Q.; Wei, G. When biomolecules meet graphene: From molecular level interactions to material design and applications. Nanoscale 2016, 8, 19491-19509. [CrossRef] [PubMed]

22. Zhang, M.F.; Li, Y.; Su, Z.Q.; Wei, G. Recent advances in the synthesis and applications of graphene-polymer nanocomposites. Polym. Chem. 2015, 6, 6107-6124. [CrossRef]

23. Wang, L.; Zhang, Y.J.; Wu, A.G.; Wei, G. Designed graphene-peptide nanocomposites for biosensor applications: A review. Anal. Chim. Acta 2017, 985, 24-40. [CrossRef] [PubMed]

24. Yang, K.; Zhang, S.A.; Zhang, G.X.; Sun, X.M.; Lee, S.T.; Liu, Z.A. Graphene in mice: Ultrahigh in vivo tumor uptake and efficient photothermal therapy. Nano Lett. 2010, 10, 3318-3323. [CrossRef] [PubMed]

25. Li, D.; Muller, M.B.; Gilje, S.; Kaner, R.B.; Wallace, G.G. Processable aqueous dispersions of graphene nanosheets. Nat. Nanotechnol. 2008, 3, 101-105. [CrossRef] [PubMed]

26. Ma, X.X.; Tao, H.Q.; Yang, K.; Feng, L.Z.; Cheng, L.; Shi, X.Z.; Li, Y.G.; Guo, L.; Liu, Z. A functionalized graphene oxide-iron oxide nanocomposite for magnetically targeted drug delivery, photothermal therapy, and magnetic resonance imaging. Nano Res. 2012, 5, 199-212. [CrossRef]

27. Mo, R.; Jiang, T.Y.; Sun, W.J.; Gu, Z. Atp-responsive DNA-graphene hybrid nanoaggregates for anticancer drug delivery. Biomaterials 2015, 50, 67-74. [CrossRef] [PubMed]

28. Bao, H.Q.; Pan, Y.Z.; Ping, Y.; Sahoo, N.G.; Wu, T.F.; Li, L.; Li, J.; Gan, L.H. Chitosan-functionalized graphene oxide as a nanocarrier for drug and gene delivery. Small 2011, 7, 1569-1578. [CrossRef] [PubMed]

29. Liu, J.Q.; Cui, L.; Losic, D. Graphene and graphene oxide as new nanocarriers for drug delivery applications. Acta Biomater. 2013, 9, 9243-9257. [CrossRef] [PubMed]

30. Goenka, S.; Sant, V.; Sant, S. Graphene-based nanomaterials for drug delivery and tissue engineering. J. Control. Release 2014, 173, 75-88. [CrossRef] [PubMed]

31. Dong, H.Q.; Dong, C.Y.; Ren, T.B.; Li, Y.Y.; Shi, D.L. Surface-engineered graphene-based nanomaterials for drug delivery. J. Biomed. Nanotechnol. 2014, 10, 2086-2106. [CrossRef] [PubMed]

32. McCallion, C.; Burthem, J.; Rees-Unwin, K.; Golovanov, A.; Pluen, A. Graphene in therapeutics delivery: Problems, solutions and future opportunities. Eur. J. Pharm. Biopharm. 2016, 104, 235-250. [CrossRef] [PubMed]

33. Ding, C.Z.; Li, Z.B. A review of drug release mechanisms from nanocarrier systems. Mater. Sci. Eng. C 2017, 76, 1440-1453. [CrossRef] [PubMed] 
34. Bahrami, B.; Hojjat-Farsangi, M.; Mohammadi, H.; Anvari, E.; Ghalamfarsa, G.; Yousefi, M.; Jadiidi-Niaragh, F. Nanoparticles and targeted drug delivery in cancer therapu. Immunol. Lett. 2017, 190, 64-83. [CrossRef] [PubMed]

35. Wang, H.X.; Sun, D.M.; Zhao, N.N.; Yang, X.C.; Shi, Y.Z.; Li, J.F.; Su, Z.Q.; Wei, G. Thermo-sensitive graphene oxide-polymer nanoparticle hybrids: Synthesis, characterization, biocompatibility and drug delivery. J. Mater. Chem. B 2014, 2, 1362-1370. [CrossRef]

36. Swain, A.K.; Pradhan, L.; Bahadur, D. Polymer stabilized fe3o4-graphene as an amphiphilic drug carrier for thermo-chemotherapy of cancer. ACS Appl. Mater. Interfaces 2015, 7, 8013-8022. [CrossRef] [PubMed]

37. Ma, X.; Qu, Q.Y.; Zhao, Y.; Luo, Z.; Zhao, Y.; Ng, K.W.; Zhao, Y.L. Graphene oxide wrapped gold nanoparticles for intracellular raman imaging and drug delivery. J. Mater. Chem. B 2013, 1, 6495-6500. [CrossRef]

38. Shi, J.J.; Wang, L.; Zhang, J.; Ma, R.; Gao, J.; Liu, Y.; Zhang, C.F.; Zhang, Z.Z. A tumor-targeting near-infrared laser-triggered drug delivery system based on go@ag nanoparticles for chemo-photothermal therapy and X-ray imaging. Biomaterials 2014, 35, 5847-5861. [CrossRef] [PubMed]

39. Yao, X.X.; Niu, X.X.; Ma, K.X.; Huang, P.; Grothe, J.; Kaskel, S.; Zhu, Y.F. Graphene quantum dots-capped magnetic mesoporous silica nanoparticles as a multifunctional platform for controlled drug delivery, magnetic hyperthermia, and photothermal therapy. Small 2017, 13, 1602225. [CrossRef] [PubMed]

40. Bai, J.; Liu, Y.W.; Jiang, X.E. Multifunctional peg-go/cus nanocomposites for near-infrared chemo-photothermal therapy. Biomaterials 2014, 35, 5805-5813. [CrossRef] [PubMed]

41. Chen, J.Q.; Liu, H.Y.; Zhao, C.B.; Qin, G.Q.; Xi, G.N.; Li, T.; Wang, X.P.; Chen, T.S. One-step reduction and pegylation of graphene oxide for photothermally controlled drug delivery. Biomaterials 2014, 35, 4986-4995. [CrossRef] [PubMed]

42. Weaver, C.L.; LaRosa, J.M.; Luo, X.L.; Cui, X.T. Electrically controlled drug delivery from graphene oxide nanocomposite films. ACS Nano 2014, 8, 1834-1843. [CrossRef] [PubMed]

43. Park, Y.H.; Park, S.Y.; In, I. Direct noncovalent conjugation of folic acid on reduced graphene oxide as anticancer drug carrier. J. Ind. Eng. Chem. 2015, 30, 190-196. [CrossRef]

44. Liu, K.P.; Wang, Y.M.; Li, H.M.; Duan, Y.X. A facile one-pot synthesis of starch functionalized graphene as nano-carrier for ph sensitive and starch-mediated drug delivery. Colloid. Surf. B 2015, 128, 86-93. [CrossRef] [PubMed]

45. Qiu, J.C.; Zhang, R.B.; Li, J.H.; Sang, Y.H.; Tang, W.; Gil, P.R.; Liu, H. Fluorescent graphene quantum dots as traceable, ph-sensitive drug delivery systems. Int. J. Nanomed. 2015, 10, 6709-6724.

46. Wang, G.S.; Ma, Y.Y.; Wei, Z.Y.; Qi, M. Development of multifunctional cobalt ferrite/graphene oxide nanocomposites for magnetic resonance imaging and controlled drug delivery. Chem. Eng. J. 2016, 289, 150-160. [CrossRef]

47. Fan, X.J.; Jiao, G.Z.; Gao, L.; Jin, P.F.; Li, X. The preparation and drug delivery of a graphene-carbon nanotube- $\mathrm{Fe}_{3} \mathrm{O}_{4}$ nanoparticle hybrid. J. Mater. Chem. B 2013, 1, 2658-2664. [CrossRef]

48. Chen, T.; Yu, H.; Yang, N.E.; Wang, M.D.; Ding, C.D.; Fu, J.J. Graphene quantum dot-capped mesoporous silica nanoparticles through an acid-cleavable acetal bond for intracellular drug delivery and imaging. J. Mater. Chem. B 2014, 2, 4979-4982. [CrossRef]

49. Jung, H.S.; Lee, M.Y.; Kong, W.H.; Do, I.H.; Hahn, S.K. Nano graphene oxide-hyaluronic acid conjugate for target specific cancer drug delivery. RSC Adv. 2014, 4, 14197-14200. [CrossRef]

50. Song, E.Q.; Han, W.Y.; Li, C.; Cheng, D.; Li, L.R.; Liu, L.C.; Zhu, G.Z.; Song, Y.; Tan, W.H. Hyaluronic acid-decorated graphene oxide nanohybrids as nanocarriers for targeted and ph-responsive anticancer drug delivery. ACS Appl. Mater. Interfaces 2014, 6, 11882-11890. [CrossRef] [PubMed]

51. Wang, C.; Chen, B.B.; Zou, M.J.; Cheng, G. Cyclic rgd-modified chitosan/graphene oxide polymers for drug delivery and cellular imaging. Colloid. Surf. B 2014, 122, 332-340. [CrossRef] [PubMed]

52. Pan, Q.X.; Lv, Y.; Williams, G.R.; Tao, L.; Yang, H.H.; Li, H.Y.; Zhu, L.M. Lactobionic acid and carboxymethyl chitosan functionalized graphene oxide nanocomposites as targeted anticancer drug delivery systems. Carbohydr. Polym. 2016, 151, 812-820. [CrossRef] [PubMed]

53. Huang, C.L.; Huang, C.C.; Mai, F.D.; Yen, C.L.; Tzing, S.H.; Hsieh, H.T.; Lingd, Y.C.; Chang, J.Y. Application of paramagnetic graphene quantum dots as a platform for simultaneous dual-modality bioimaging and tumor-targeted drug delivery. J. Mater. Chem. B 2015, 3, 651-664. [CrossRef] 
54. Jiang, T.Y.; Sun, W.J.; Zhu, Q.W.; Burns, N.A.; Khan, S.A.; Mo, R.; Gu, Z. Furin-mediated sequential delivery of anticancer cytokine and small-molecule drug shuttled by graphene. Adv. Mater. 2015, 27, 1021-1028. [CrossRef] [PubMed]

55. Chowdhury, S.M.; Surhland, C.; Sanchez, Z.; Chaudhary, P.; Kumar, M.A.S.; Lee, S.; Pena, L.A.; Waring, M.; Sitharaman, B.; Naidu, M. Graphene nanoribbons as a drug delivery agent for lucanthone mediated therapy of glioblastoma multiforme. Nanomed. Nanotechnol. 2015, 11, 109-118. [CrossRef] [PubMed]

56. Chen, H.; Wang, Z.Y.; Zong, S.F.; Wu, L.; Chen, P.; Zhu, D.; Wang, C.L.; Xu, S.H.; Cui, Y.P. Sers-fluorescence monitored drug release of a redox-responsive nanocarrier based on graphene oxide in tumor cells. ACS Appl. Mater. Interfaces 2014, 6, 17526-17533. [CrossRef] [PubMed]

57. Zhao, X.B.; Liu, L.; Li, X.R.; Zeng, J.; Jia, X.; Liu, P. Biocompatible graphene oxide nanoparticle-based drug delivery platform for tumor microenvironment-responsive triggered release of doxorubicin. Langmuir 2014, 30, 10419-10429. [CrossRef] [PubMed]

58. Yin, T.J.; Liu, J.Y.; Zhao, Z.K.; Zhao, Y.Y.; Dong, L.H.; Yang, M.; Zhou, J.P.; Huo, M.R. Redox sensitive hyaluronic acid-decorated graphene oxide for photothermally controlled tumor-cytoplasmselective rapid drug delivery. Adv. Funct. Mater. 2017, 27, 1604620. [CrossRef]

59. Song, J.B.; Yang, X.Y.; Jacobson, O.; Lin, L.S.; Huang, P.; Niu, G.; Ma, Q.J.; Chen, X.Y. Sequential drug release and enhanced photothermal and photoacoustic effect of hybrid reduced graphene oxide-loaded ultrasmall gold nanorod vesicles for cancer therapy. ACS Nano 2015, 9, 9199-9209. [CrossRef] [PubMed]

60. Tang, Y.X.; Hu, H.; Zhang, M.G.; Song, J.B.; Nie, L.M.; Wang, S.J.; Niu, G.; Huang, P.; Lu, G.M.; Chen, X.Y. An aptamer-targeting photoresponsive drug delivery system using "off-on" graphene oxide wrapped mesoporous silica nanoparticles. Nanoscale 2015, 7, 6304-6310. [CrossRef] [PubMed]

61. Kim, H.; Lee, D.; Kim, J.; Kim, T.I.; Kim, W.J. Photothermally triggered cytosolic drug delivery via endosome disruption using a functionalized reduced graphene oxide. ACS Nano 2013, 7, 6735-6746. [CrossRef] [PubMed]

62. Gao, H.F.; Yang, W.L.; Min, K.; Zha, L.S.; Wang, C.C.; Fu, S.K. Thermosensitive poly(n-isopropylacrylamide) nanocapsules with controlled permeability. Polymer 2005, 46, 1087-1093. [CrossRef]

63. Al-Ahmady, Z.S.; Al-Jamal, W.T.; Bossche, J.V.; Bui, T.T.; Drake, A.F.; Mason, A.J.; Kostarelos, K. Lipid-peptide vesicle nanoscale hybrids for triggered drug release by mild hyperthermia in vitro and in vivo. ACS Nano 2012, 6, 9335-9346. [CrossRef] [PubMed]

64. Ruiz-Hernandez, E.; Baeza, A.; Vallet-Regi, M. Smart drug delivery through DNA/magnetic nanoparticle gates. ACS Nano 2011, 5, 1259-1266. [CrossRef] [PubMed]

65. Rapoport, N.Y.; Kennedy, A.M.; Shea, J.E.; Scaife, C.L.; Nam, K.H. Controlled and targeted tumor chemotherapy by ultrasound-activated nanoemulsions/microbubbles. J. Control. Release 2009, 138, 268-276. [CrossRef] [PubMed]

66. Xiao, Z.Y.; Ji, C.W.; Shi, J.J.; Pridgen, E.M.; Frieder, J.; Wu, J.; Farokhzad, O.C. DNA self-assembly of targeted near-infrared-responsive gold nanoparticles for cancer thermo-chemotherapy. Angew. Chem. Int. Ed. 2012, 51, 11853-11857. [CrossRef] [PubMed]

67. Yan, Q.; Yuan, J.Y.; Cai, Z.N.; Xin, Y.; Kang, Y.; Yin, Y.W. Voltage-responsive vesicles based on orthogonal assembly of two homopolymers. J. Am. Chem. Soc. 2010, 132, 9268-9270. [CrossRef] [PubMed]

68. Koren, E.; Apte, A.; Jani, A.; Torchilin, V.P. Multifunctional pegylated 2c5-immunoliposomes containing ph-sensitive bonds and tat peptide for enhanced tumor cell internalization and cytotoxicity. J. Control. Release 2012, 160, 264-273. [CrossRef] [PubMed]

69. Xiong, M.H.; Bao, Y.; Yang, X.Z.; Wang, Y.C.; Sun, B.L.; Wang, J. Lipase-sensitive polymeric triple-layered nanogel for "on-demand" drug delivery. J. Am. Chem. Soc. 2012, 134, 4355-4362. [CrossRef] [PubMed]

70. Ryu, J.H.; Chacko, R.T.; Jiwpanich, S.; Bickerton, S.; Babu, R.P.; Thayumanavan, S. Self-cross-linked polymer nanogels: A versatile nanoscopic drug delivery platform. J. Am. Chem. Soc. 2010, 132, 17227-17235. [CrossRef] [PubMed]

71. Wilson, D.S.; Dalmasso, G.; Wang, L.X.; Sitaraman, S.V.; Merlin, D.; Murthy, N. Orally delivered thioketal nanoparticles loaded with tnf-alpha-sirna target inflammation and inhibit gene expression in the intestines. Nat. Mater. 2010, 9, 923-928. [CrossRef] [PubMed]

72. Han, D.H.; Tong, X.; Zhao, Y. Block copolymer micelles with a dual-stimuli-responsive core for fast or slow degradation. Langmuir 2012, 28, 2327-2331. [CrossRef] [PubMed] 
73. Dai, J.; Lin, S.D.; Cheng, D.; Zou, S.Y.; Shuai, X.T. Interlayer-crosslinked micelle with partially hydrated core showing reduction and ph dual sensitivity for pinpointed intracellular drug release. Angew. Chem. Int. Ed. 2011, 50, 9404-9408. [CrossRef] [PubMed]

74. Baeza, A.; Guisasola, E.; Ruiz-Hernandez, E.; Vallet-Regi, M. Magnetically triggered multidrug release by hybrid mesoporous silica nanoparticles. Chem. Mater. 2012, 24, 517-524. [CrossRef]

75. Mura, S.; Nicolas, J.; Couvreur, P. Stimuli-responsive nanocarriers for drug delivery. Nat. Mater. 2013, 12, 991-1003. [CrossRef] [PubMed]

76. Nahire, R.; Paul, S.; Scott, M.D.; Singh, R.K.; Muhonen, W.W.; Shabb, J.; Gange, K.N.; Srivastava, D.K.; Sarkar, K.; Mallik, S. Ultrasound enhanced matrix metalloproteinase-9 triggered release of contents from echogenic liposomes. Mol. Pharm. 2012, 9, 2554-2564. [CrossRef] [PubMed]

77. Zhou, L.; Zhou, L.; Wei, S.; Ge, X.; Zhou, J.; Jiang, H.; Li, F.; Shen, J. Combination of chemotherapy and photodynamic therapy using graphene oxide as drug delivery system. J. Photochem. Photobiol. B 2014, 135, 7-16. [CrossRef] [PubMed]

78. Wang, X.J.; Sun, X.; Lao, J.; He, H.; Cheng, T.T.; Wang, M.Q.; Wang, S.J.; Huang, F. Multifunctional graphene quantum dots for simultaneous targeted cellular imaging and drug delivery. Colloids Surf. B 2014, 122, 638-644. [CrossRef] [PubMed]

79. Wang, Y.S.; Polavarapu, L.; Liz-Marzan, L.M. Reduced graphene oxide-supported gold nanostars for improved sers sensing and drug delivery. ACS Appl. Mater. Interfaces 2014, 6, 21798-21805. [CrossRef] [PubMed]

80. Wang, G.S.; Chen, G.Y.; Wei, Z.Y.; Dong, X.F.; Qi, M. Multifunctional fe3o4/graphene oxide nanocomposites for magnetic resonance imaging and drug delivery. Mater. Chem. Phys. 2013, 141, 997-1004. [CrossRef]

81. Yan, L.; Chang, Y.N.; Zhao, L.N.; Gu, Z.J.; Liu, X.X.; Tian, G.; Zhou, L.J.; Ren, W.L.; Jin, S.; Yin, W.Y.; et al. The use of polyethylenimine-modified graphene oxide as a nanocarrier for transferring hydrophobic nanocrystals into water to produce water-dispersible hybrids for use in drug delivery. Carbon 2013, 57, 120-129. [CrossRef]

82. Wu, H.X.; Shi, H.L.; Wang, Y.P.; Jia, X.Q.; Tang, C.Z.; Zhang, J.M.; Yang, S.P. Hyaluronic acid conjugated graphene oxide for targeted drug delivery. Carbon 2014, 69, 379-389. [CrossRef]

83. Song, Z.Q.; Xu, Y.H.; Yang, W.R.; Cui, L.; Zhang, J.Z.; Liu, J.Q. Graphene/tri-block copolymer composites prepared via raft polymerizations for dual controlled drug delivery via ph stimulation and biodegradation. Eur. Polym. J. 2015, 69, 559-572. [CrossRef]

84. Yang, H.H.; Bremner, D.H.; Tao, L.; Li, H.Y.; Hu, J.; Zhu, L.M. Carboxymethyl chitosan-mediated synthesis of hyaluronic acid-targeted graphene oxide for cancer drug delivery. Carbohydr. Polym. 2016, 135, 72-78. [CrossRef] [PubMed]

85. Hu, S.H.; Fang, R.H.; Chen, Y.W.; Liao, B.J.; Chen, I.W.; Chen, S.Y. Photoresponsive protein-graphene-protein hybrid capsules with dual targeted heat-triggered drug delivery approach for enhanced tumor therapy. Adv. Funct. Mater. 2014, 24, 4144-4155. [CrossRef]

86. Wang, H.; Gu, W.; Xiao, N.; Ye, L.; Xu, Q.Y. Chlorotoxin-conjugated graphene oxide for targeted delivery of an anticancer drug. Int. J. Nanomed. 2014, 9, 1433-1442.

87. Wu, J.H.; Chen, A.P.; Qin, M.; Huang, R.; Zhang, G.; Xue, B.; Wei, J.W.; Li, Y.; Cao, Y.; Wang, W. Hierarchical construction of a mechanically stable peptide-graphene oxide hybrid hydrogel for drug delivery and pulsatile triggered release in vivo. Nanoscale 2015, 7, 1655-1660. [CrossRef] [PubMed]

88. Li, Y.; Liu, Y.; Fu, Y.J.; Wei, T.T.; Le Guyader, L.; Gao, G.; Liu, R.S.; Chang, Y.Z.; Chen, C.Y. The triggering of apoptosis in macrophages by pristine graphene through the mapk and tgf-beta signaling pathways. Biomaterials 2012, 33, 402-411. [CrossRef] [PubMed]

89. Duch, M.C.; Budinger, G.R.S.; Liang, Y.T.; Soberanes, S.; Urich, D.; Chiarella, S.E.; Campochiaro, L.A.; Gonzalez, A.; Chandel, N.S.; Hersam, M.C.; et al. Minimizing oxidation and stable nanoscale dispersion improves the biocompatibility of graphene in the lung. Nano Lett. 2011, 11, 5201-5207. [CrossRef] [PubMed]

90. Yang, Z.X.; Ge, C.C.; Liu, J.J.; Chong, Y.; Gu, Z.L.; Jimenez-Cruz, C.A.; Chai, Z.F.; Zhou, R.H. Destruction of amyloid fibrils by graphene through penetration and extraction of peptides. Nanoscale 2015, 7, 18725-18737. [CrossRef] [PubMed]

(C) 2017 by the authors. Licensee MDPI, Basel, Switzerland. This article is an open access article distributed under the terms and conditions of the Creative Commons Attribution (CC BY) license (http://creativecommons.org/licenses/by/4.0/). 